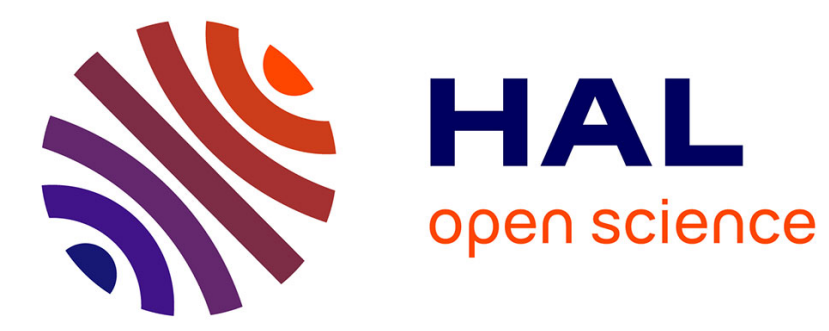

\title{
Direct Thrust Measurement of an Electron Cyclotron Resonance Plasma Thruster
}

Théo Vialis, Julien Jarrige, Denis Packan, Ane Aanesland

\section{To cite this version:}

Théo Vialis, Julien Jarrige, Denis Packan, Ane Aanesland. Direct Thrust Measurement of an Electron Cyclotron Resonance Plasma Thruster. Journal of Propulsion and Power, 2018, pp.1-11. 10.2514/1.B37036 . hal-01849176

\section{HAL Id: hal-01849176 https://hal.science/hal-01849176}

Submitted on 25 Jul 2018

HAL is a multi-disciplinary open access archive for the deposit and dissemination of scientific research documents, whether they are published or not. The documents may come from teaching and research institutions in France or abroad, or from public or private research centers.
L'archive ouverte pluridisciplinaire HAL, est destinée au dépôt et à la diffusion de documents scientifiques de niveau recherche, publiés ou non, émanant des établissements d'enseignement et de recherche français ou étrangers, des laboratoires publics ou privés. 


\title{
Direct thrust measurement of an Electron Cyclotron Resonance plasma thruster
}

\author{
Théo Vialis, ${ }^{1}$ Julien Jarrige ${ }^{2}$ and Denis Packan ${ }^{3}$ \\ ONERA, Université Paris Saclay, F-91123 Palaiseau - France \\ Ane Aanesland ${ }^{4}$ \\ Laboratoire de Physique des Plasmas, Palaiseau, 91120, France
}

${ }^{1} \mathrm{PhD}$ student, DPHY department (Physics, Instrumentation, Environment and Space)

${ }^{2}$ Research Scientist, DPHY department (Physics, Instrumentation, Environment and Space)

${ }^{3}$ Research Scientist, DPHY department (Physics, Instrumentation, Environment and Space)

${ }^{4}$ Research Scientist, CNRS, Ecole Polytechnique, Sorbonne Universités, UPMC Univ. Paris 06, Univ. Paris-Sud 
Direct thrust measurements of an Electron Cyclotron Resonance plasma thruster are performed with a thrust balance. The thruster performances are deduced, and the influence of power and mass-flow rate is studied. The measured thrust is around $1 \mathrm{mN}$ for $50 \mathrm{~W}$ of microwave power input and $0.1 \mathrm{mg} / \mathrm{s}$ of xenon, corresponding to $1000 \mathrm{~s}$ of specific impulse and $11 \%$ of total efficiency. It is found that the thrust is increased by $25 \%$ when the walls of the plasma source are covered with a dielectric layer. Comparisons are made between the direct thrust measurements and the indirect thrust measurements obtained with electrostatic probes in the plasma beam.

\section{Nomenclature}

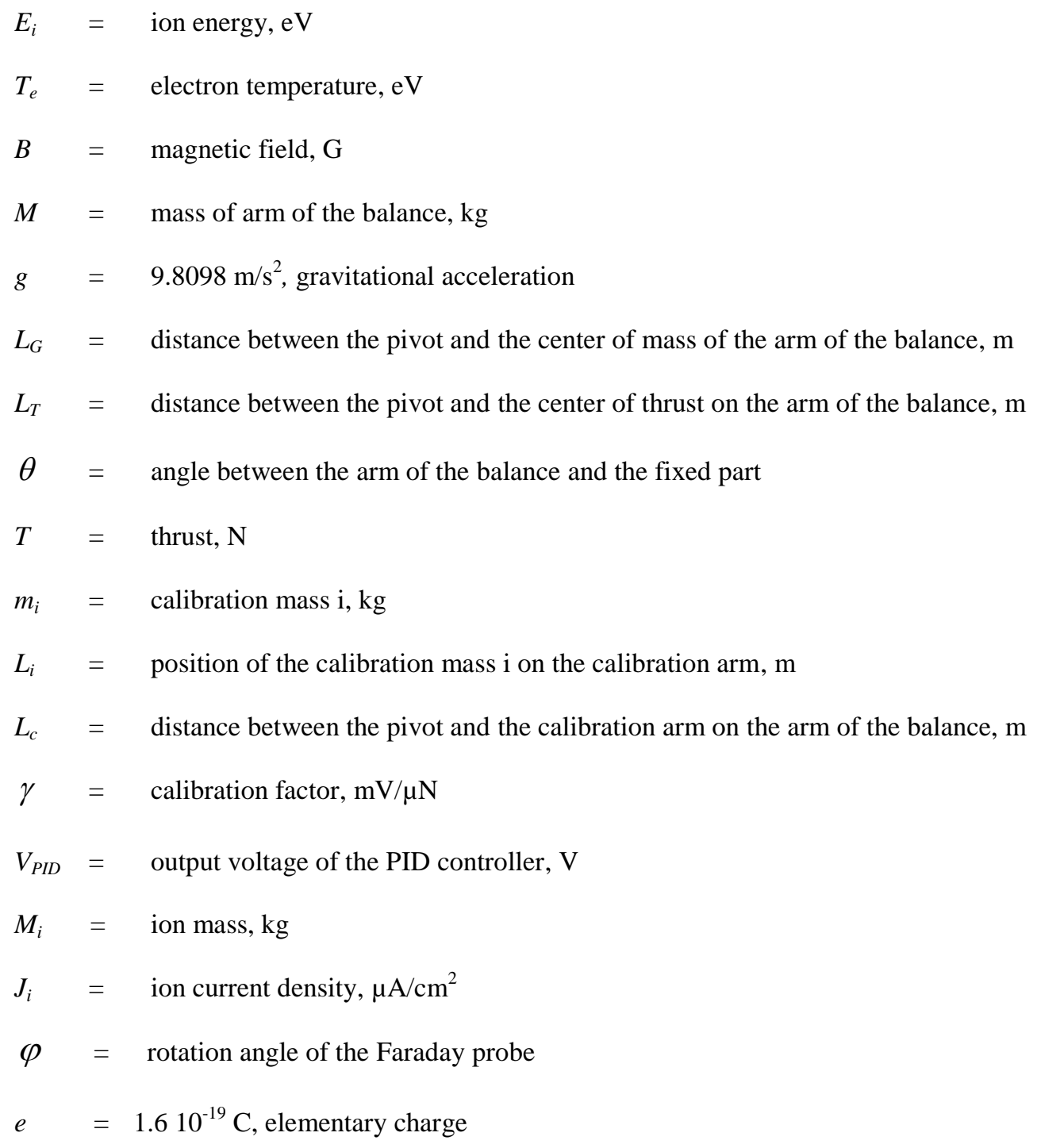




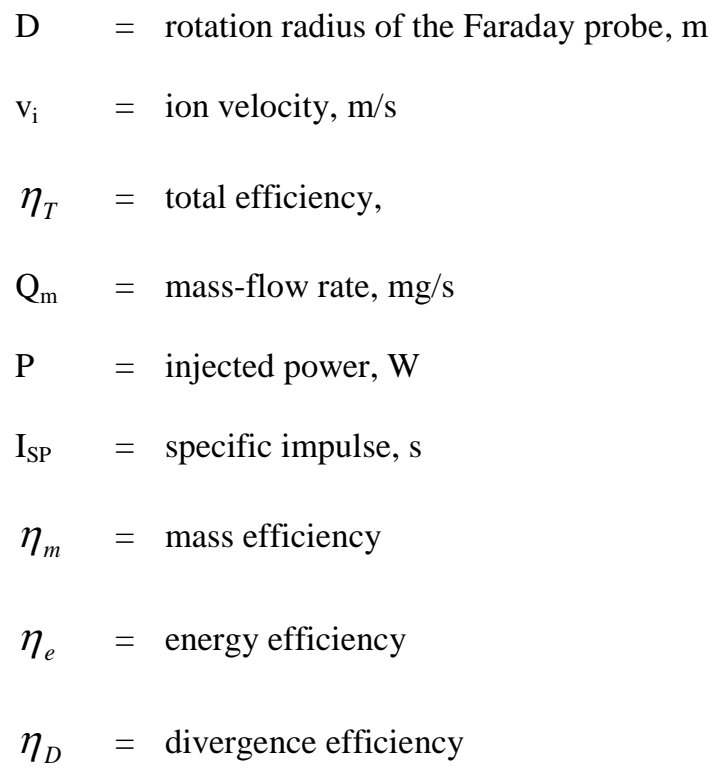

\section{Introduction}

1 LECTRODELESS plasma thrusters are an alternative technology to the well-known Gridded Ion Engines and Hall Thrusters. The advantage of the concept is the quasi-neutrality of the plasma that is expelled: there is no need for a neutralization cathode, which is one of the most fragile components in ion and hall thrusters, and which are very sensitive to impurities in the propellant. This leads to a potentially higher reliability, longer lifetime, and lower development and recurring costs for electrodeless thrusters. But the complexity of the underlying physics involved is so far limiting the development of this technology. One of the main difficulties is to model with enough precision all the mechanisms occurring simultaneously in the thruster such as ionization and plasma acceleration.

The main electrodeless technologies that are currently being developed are the Helicon Plasma Thruster (HPT), the Electron Cyclotron Resonance (ECR) plasma thruster, and the Variable Specific Impulse Magnetoplasma Rocket (VASIMR) which is a combination of a Helicon and an ICR (Ion Cyclotron Resonance) plasma [1]. HPT and ECR thrusters use radio-frequency electromagnetic waves as power sources to heat electrons and an electron-driven magnetic nozzle to accelerate the plasma out of the chamber, whereas VASIMR relies on ion heating in an ICR source and ion acceleration in a magnetic nozzle. The HPT uses the wave-plasma coupling obtained by the propagation of Helicon waves (low frequency whistler waves [2]) in cold magnetized plasma. On the other hand, the ECR plasma thruster uses the resonant absorption [3] of microwave power (frequency of several GHz) by the electrons in a magnetized plasma in order to produce and maintain the discharge. For both technologies, the 
mechanisms that occur in the magnetic nozzle, i.e. ion acceleration and plasma detachment, are not fully understood and are still active fields of research [4].

ECR plasma thrusters have been studied since the 60s [5]. In the middle of the 90s, Sercel performed a study on an ECR engine where the microwaves are launched in the plasma source from a cylindrical waveguide [6]. Stallard and Hooper, also studied these technologies and developed a prototype based on a bi-helical antenna [7,8]. The interest into these technologies was hampered by the low efficiency of the microwave generators available at the time, and the poor vacuum conditions of the experiments (often much larger than $10^{-5}$ mbar), due to the high power and to the high mass-flow rate. Indeed it is now known that an electric thruster must be operated in a good vacuum (less than $10^{-5}$ mbar) to show good performances $[9,10]$.

Since 2010, the ECR plasma thruster technology is re-investigated and a new coaxial design has been proposed [11]. At the current development stage, the power range $(<50 \mathrm{~W})$ and the thrust range $(100 \mu \mathrm{N}$ to $1 \mathrm{mN})$ are compatible with the rising nanosat market, whose requirements are not well covered by commercially available technologies.

Previous works on ECR plasma thruster led to a better understanding of the technology $[12,13]$. An analytical discharge model of a helicon source [14] has been adapted to the ECR thruster, and has helped to understand the physical mechanisms at play [15]. Experimental parametric studies have shown that the thruster performances are very sensitive to the operating conditions; the mass-flow rate, the injected power and the magnetic field magnitude have a significant effect on the ion energy and the mass efficiency. It has also been shown that the ion energy to electron temperature ratio, $E_{i} / T_{e}$, is constant for a given magnetic field magnitude (about 4-5). This enables the use, in certain conditions, of a polytropic expansion law to model electron cooling and ion acceleration in the magnetic nozzle [16,17]. More recently, electron temperatures up to $35 \mathrm{eV}$ have been measured in the source using a diamagnetic loop diagnostic, and the electron cooling has been observed in the expansion region [18].

The thruster efficiency has been measured at $16 \%$ with a thrust level of $1 \mathrm{mN}$ using electrostatic probe measurements $[19,20]$. However, the interpretation of these measurements are difficult in magnetic nozzle plumes because of the high ion energy, the high electron temperatures, the large magnetic field (several hundreds of Gauss), which can lead to a dramatic error on the estimation of the performances. On the other hand, thrust balances, when properly designed and used, are a reliable and fast method to measure thrust, allowing complete parametric studies. Moreover, thrust balances are the industry standard [21]. 
In this paper the ECR plasma thruster is tested on a pendulum thrust balance that has been previously developed for a helicon thruster [22] at ONERA's facility. A similar thrust stand was selected by ESA and CNES to characterize cold gas micronewton thrusters for scientific mission such as GAIA, LISA-PATHFINDER, MICROSCOPE and EUCLID [23].

In the last few years several direct thrust measurements have been performed on HPT. Takahashi and Lafleur have used a double pendulum balance with a laser displacement sensor [24, 25]. They were able to measure thrusts up to $4 \mathrm{mN}$ for powers up to $700 \mathrm{~W}$. Nakamura used a torsional thrust balance with a laser displacement sensor, reaching $650 \mu \mathrm{N}$ at $400 \mathrm{~W}$ [26]. In this last work, they were able to discriminate the origin (magnetic or thermal, more detail in the next section) of the thrust.

This paper presents the first direct thrust measurements of an ECR plasma thruster with a magnetic nozzle. Section II presents the ECR thruster technology, along with the thrust balance and the measurement procedure. A parametric study on mass flow-rate and power and the effect of insulating/conducting walls are shown in section III. Finally, the direct thrust measurements are compared with electrostatic plume diagnostics in section IV.

\section{Apparatus and Methods}

\section{A. Description of the thruster technology and prototypes}

The principle of the ECR plasma thruster is described in detail in [11] and [13]. The thruster consists of a $27 \mathrm{~mm}$ diameter and $15 \mathrm{~mm}$ long semi-open coaxial plasma source (Fig. 1) in which a propulsive gas is injected and microwave power is fed. The source is immersed in a magnetic field created either by a coil or a permanent magnet. In the regions where the cyclotron frequency, which depends on the applied magnetic field, matches the frequency of the injected microwaves (e.g. $875 \mathrm{G}$ for a microwave frequency of $2.45 \mathrm{GHz}$ ), the free electrons from the plasma are heated by the electron cyclotron resonance effect, and absorb the microwave power. The electron temperature is increased up to a few tens of eV [18], and the electrons ionize the propellant gas by inelastic collisions. The energetic electrons are expelled at the open side of the cavity (exhaust) by two main processes: plasma expansion (driven by the electron pressure) and diamagnetic effects in the divergent magnetic field [25, 27-31]. The difference of mobility between the ions and the electrons creates an ambipolar electric field that maintains the quasi-neutrality of the current-free plasma beam and accelerates the ions. Finally, the electrons detach themselves from the magnetic 
field lines in the far field in order to produce a net momentum gain. Plasma detachment is still an open question and several mechanisms have been proposed [29].

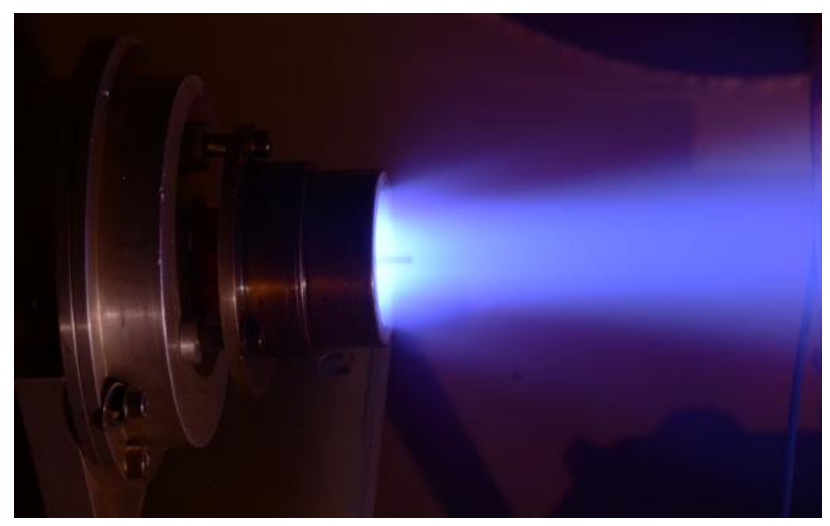

Fig. 1 Picture of the ECR-PM-V1 Thruster operating with xenon in the B09 vacuum chamber at ONERA Palaiseau.

The results presented in this paper were obtained with a permanent magnet prototype of the ECR thruster (Fig. 2). The coil version that has been extensively characterized in the previous papers [15] is not appropriate for a direct measurement on a thrust balance due to the weight of the magnetic circuit and the stiffness of the cables used to drive the current. The geometry of the source in the new permanent magnet version (ECR-PM-V1) is similar to the coil version. The magnetic field topology of this new version is shown in Fig. 3. An annular magnet made of Nd-FeB (26 mm inner diameter, $70 \mathrm{~mm}$ outer diameter, $25 \mathrm{~mm}$ thickness) is located at the back of the plasma source (see Fig. 2). The propellant is injected through two holes ( $2 \mathrm{~mm}$ in diameter) in a dielectric (boron nitride) back plate.

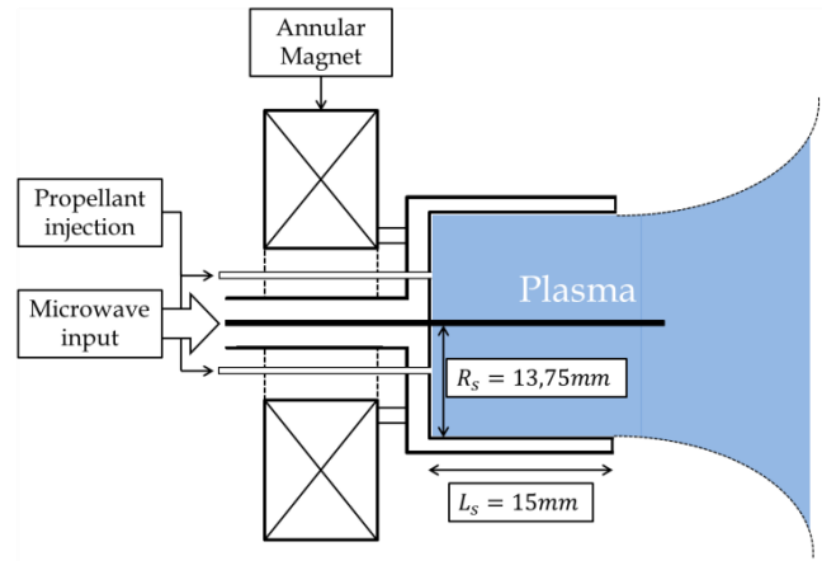

Fig. 2 Schematic of the ECR-PM-V1 thruster (not in scale). 
The ECR zone, i.e. the zone where the magnetic field magnitude is around $B_{E C R}(G) \approx 357.4 \times f(G H z)$ (colored zone in Fig. 3), can be moved inside the cavity by adjusting the distance between the source and the magnet. All the results presented in this paper are obtained with the ECR zone between 0.5 and $1 \mathrm{~mm}$ from the backplate.

The thruster is electrically isolated from the facility ground with a DC-Block, so the plume is current-free. The thruster source is floating at the thruster potential, which depends on the electron temperature in the source and is directly proportional to the ion mean energy, as shown in [12].

The inner conductor (the antenna) is a $1.7 \mathrm{~mm}$ cylinder made of nonmagnetic stainless steel. All the other metallic parts of the thruster are made of aluminum alloy. In some experiments (see Section III.C), the inner part of the external cylinder is covered by polyimide tape in order to electrically insulate the thruster from the plasma.

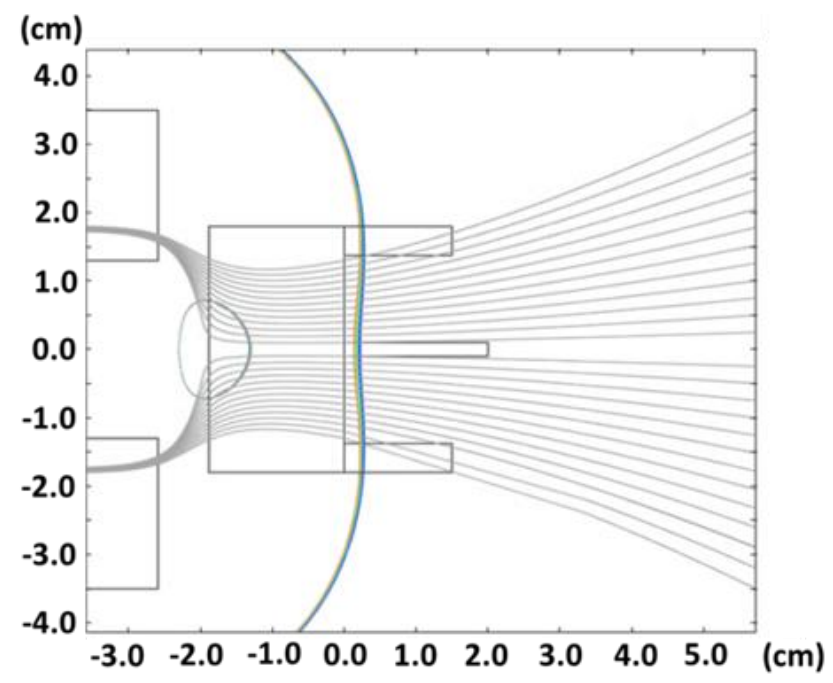

Fig. 3 Magnetic field topology of the ECR-PM-V1 Thruster. The colored zone is the ECR zone. The lengths are in centimeters.

For this new prototype, an experimental investigation on the influence of the parameters has been performed in order to find the optimal operating conditions.

The ECR-PM-V1 prototype is typically operated with microwave input powers in the range 20-60 W, and with xenon mass-flow rates in the range $0.05-0.2 \mathrm{mg} / \mathrm{s}$.

The microwave generator is a combination of a commercial signal generator (Kuhne KUSG245) and an amplifier (KUPA 2325E). It can deliver power from $0 \mathrm{~W}$ to $100 \mathrm{~W}$, with an adjustable frequency from $2.3 \mathrm{GHz}$ to 
2.6 GHz. The mass flow rate is controlled with a Bronkhorst "EL-FLOW" regulator ( $1 \mathrm{mg} / \mathrm{s}$ full range) calibrated for xenon.

All the results presented in this paper are obtained with a microwave frequency of $2.45 \mathrm{GHz}$. The experiments are performed in the $4 \mathrm{~m}$ long and $1 \mathrm{~m}$ in diameter, B61 vacuum chamber at ONERA Palaiseau center. The secondary pumping is ensured by a "Pfeiffer TPH2200" turbo-molecular pump (1 000 1/s for xenon) and a cryogenic system (7 000 1/s for xenon). The base pressure is about $10^{-7}$ mbar. The pressure is measured by a MKS999 Quattro vacuum transducer and is typically about $5 \times 10^{-6}$ mbar when the thruster is operated at $0.1 \mathrm{mg} / \mathrm{s}$.

\section{B. Balance Principle}

The pendulum thrust balance is a vertical pendulum balance with a quasi-frictionless pivot. The thruster is mounted at the end of the arm (Fig. 4).

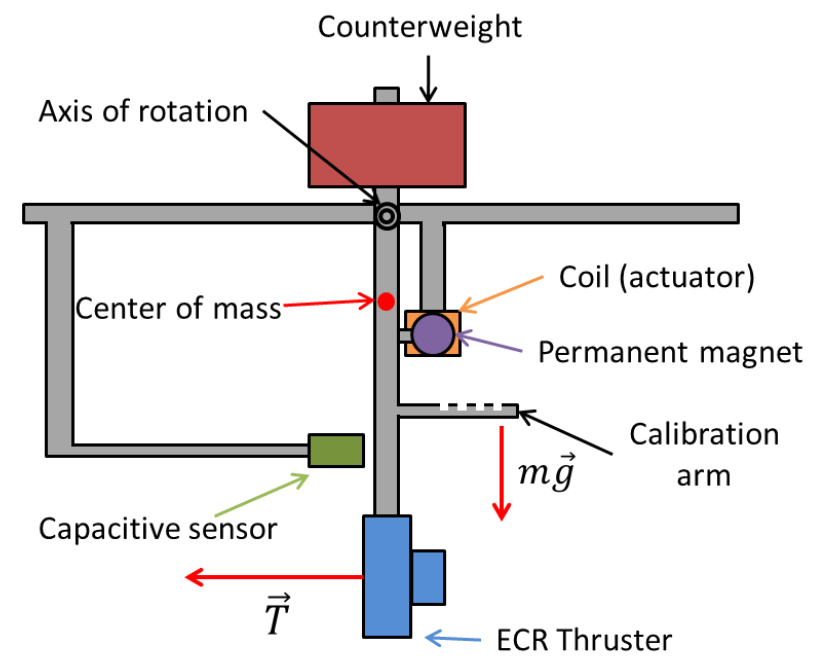

Fig. 4 Schematic of the thrust balance.

When the thruster is operated, the produced thrust creates a torque on the arm. At the steady state, the torques of the thrust and of the arm weight cancel each other (Fig. 5). One can obtain an expression for the thrust, using the equation of the equilibrium of the torques: 


$$
T=M g \frac{L_{G}}{L_{T}} \sin (\theta)
$$

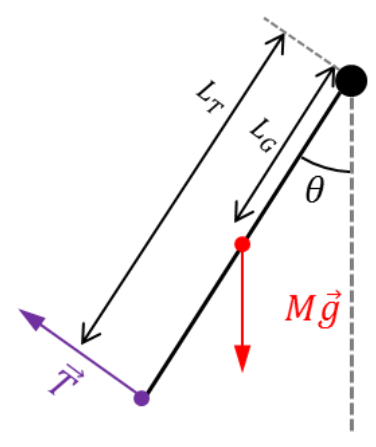

\section{Fig. 5 Principle of the pendulum balance.}

The absolute value of the thrust is directly proportional to the sine of the angle. Two different types of sensors are placed on the pendulum: a Honeywell QA 700 accelerometer, which is used to assess the initial verticality of the arm (without thrust), and a FOGALE MC900 capacitive sensor, which is used to measure the displacement because of its higher signal-to-noise ratio.

In order to adjust the horizontality for the initial tuning of the balance, another accelerometer is placed on the static part of the balance.

One can estimate the order of magnitude of the tilt angle from the eq. (1). Taking $\mathrm{T}=1 \mathrm{mN}, \mathrm{M}=1 \mathrm{~kg}$ (mass of the thruster and the pendulum arm) and $L_{T}=3 L_{G}$, the angle would be $\theta=0.02^{\circ}(\sim 0.1 \mathrm{~mm}$ of displacement $)$. The capacitive sensor must then have a resolution high enough to detect the small displacement of the arm. Experiments with a similar balance [19] have shown that non-linearity and hysteresis effects can appear when the arm is moving, due to the pivot or cables attached. The balance has been modified with a PID loop to be operated in "null mode", where the arm is kept vertical while the thrust is applied. The same method has recently been used by Kakami [32].

\section{PID control system}

A PID (Proportional, Integrator, Derivator) control system (shown in Fig. 6) is added in order to keep the balance arm at its equilibrium position. The signal from the capacitive sensor is fed to the analog PID controller (SRS SIM960). The output signal (correction of the controller) is sent to a planar coil actuator that is placed near a permanent magnet which is attached on the arm. When the voltage from the PID is applied to the coil, the resulting 
magnetic field interacts with the permanent magnet and produces a force that can move the arm or, in the present case, prevent it to move.

The output voltage from the PID controller is theoretically proportional to the torque applied on the arm. With a proper calibration, the PID output signal can be used as a thrust signal. The parameters of the PID controller (proportional gain $K_{p}$, derivative coefficient $K_{d}$ and integral coefficient $K_{i}$ ) have been adjusted in order to obtain a reasonable time response, while limiting the overshoot, the number of oscillations and the static error. The setpoint of the controller is set at $0 \mathrm{~V}$ (capacitive sensor), corresponding to the value at rest.

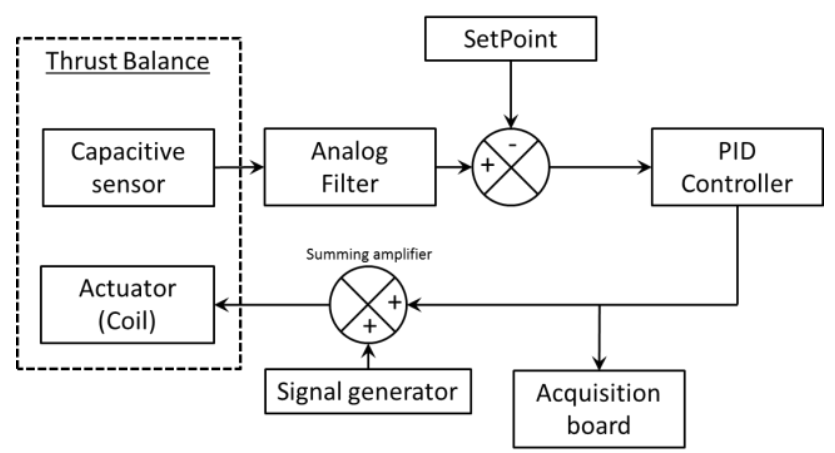

Fig. 6 Logic diagram of the PID control system with the capacitive sensor as an input and the planar coil as the actuator for the output.

The response of the PID control to a step of thrust is shown in Fig. 7. A signal generator (in Fig. 6) plugged on a SRS SIM980 "Summing Amplifier" is used to apply a step signal to the actuator (Coil) in order to simulate a step of thrust. With the settings used for the PID controller, the time response of the regulation is about $5 \mathrm{~s}$, which is short enough for the post-processing. The PID signal on Fig. 7 is post-processed with a centered $(0.4 \mathrm{~Hz})$ moving average, which is a non-causal low-pass filter. This is why the post-processed PID signal starts rising slightly before the step of simulated thrust. The post-processing methods of the signals are more detailed in section E. 


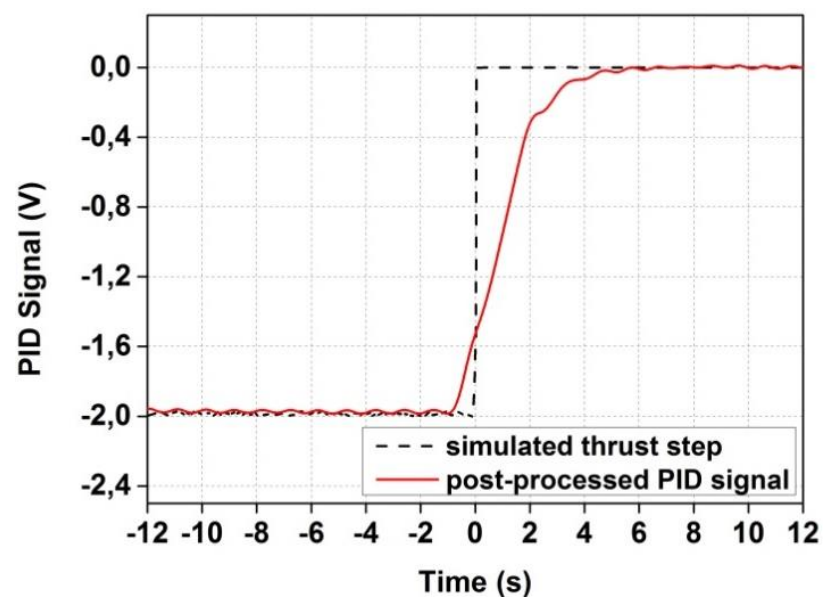

Fig. 7 Example of the PID response to a simulate thrust step. The 100 points adjacent-averaged smooth is superimposed to the thrust step applied.

\section{Thrust Calibration}

The PID output signal obtained during the acquisition is converted into an absolute thrust value through a calibration method, where small masses are successively deposited on a calibration arm with a vacuum-rated translation stage. The purpose of this operation is to obtain the value of the calibration coefficient and to verify the linearity of the balance response over the whole thrust range (see [23]).

The weights of the calibration masses, $m_{i} g$, are measured precisely using a Mettler Toledo balance with an accuracy of $0.01 \mathrm{mg}$. The torque equation for the calibration can be written as:

$$
T_{i}=\frac{L_{i}}{L_{c}} m_{i} g+O(\theta)
$$

where $L_{i}$ is the mass position on the calibration arm and $L_{C}$ is the arm length $\left(0.394 \pm 2 \times 10^{-3} \mathrm{~m}\right)$.

The length of the balance arm $\left(L_{c}\right)$, the positions of the calibration masses $\left(L_{i}\right)$ and their weight are known. So, the theoretical value of the "equivalent" thrust (the torque) produced by the calibration masses is determined with a good accuracy using eq. (2). The PID signal is measured for each deposited mass, and the calibration factor $\gamma_{i}$ can be deduced (ratio of the PID step signal to the "equivalent" thrust): 


$$
\gamma_{i}=\frac{V_{i}}{T_{i}}
$$

Table 1 lists the different masses, their positions on the calibration arm and the cumulated equivalent thrust yielded. This span of equivalent thrust covers the range of thrust expected with the current version of the ECR thruster.

Table 1 Calibration masses and their position on the calibration arm

\begin{tabular}{c|c|c}
\hline Masses (mg) & Position (mm) & Eq thrust $(\boldsymbol{\mu N})$ \\
\hline 197.5 & 27.5 & 135.23 \\
228.64 & 32.5 & 320.25 \\
313.4 & 42.5 & 651.88 \\
335.12 & 47.5 & 1048.22 \\
336.75 & 52.5 & 1488.41 \\
\hline
\end{tabular}

Fig. 8 (top) shows a typical acquisition of the output PID signal during a mass deposition. The uncertainty bars come from the error budget explained in Table 2 (section III-A). 

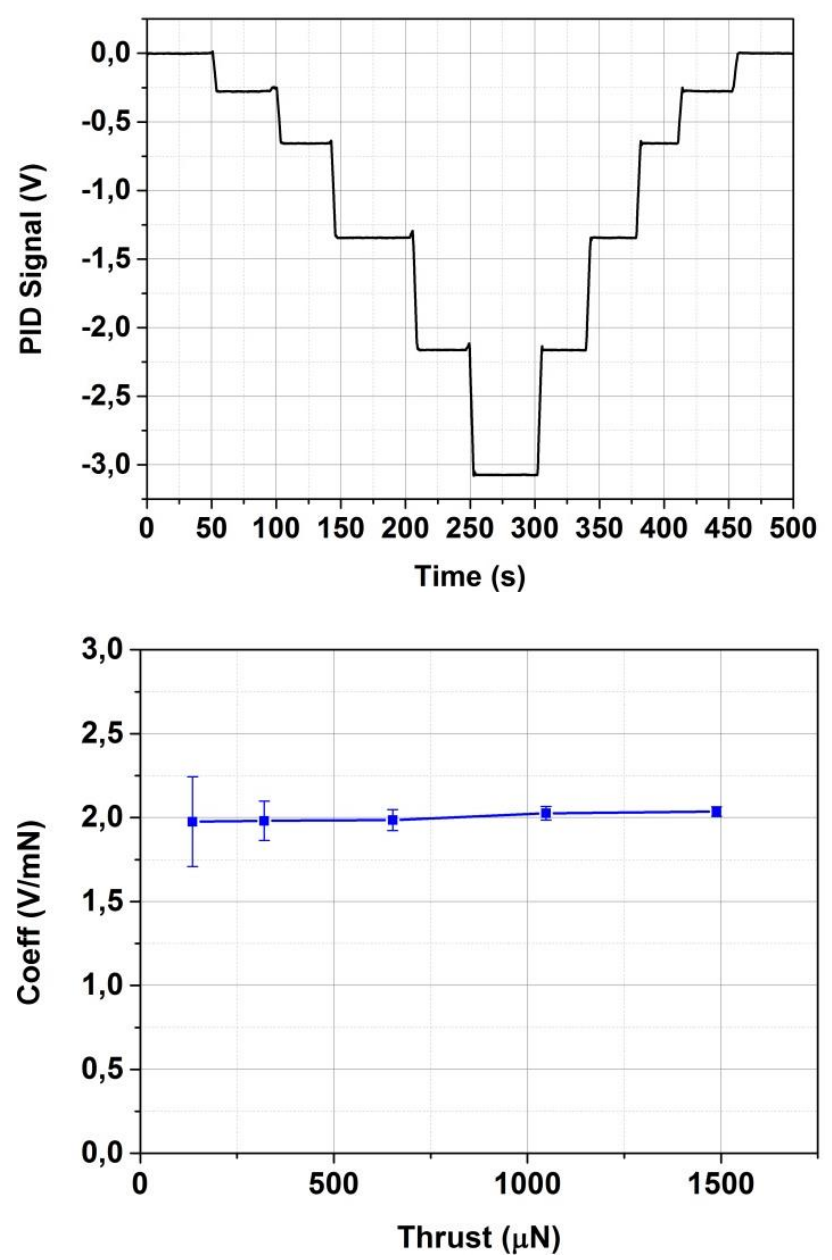

Fig. 8 Example of balance calibrationwith the five masses. PID signal (top) and corresponding calibration factor $\gamma_{i}$ (bottom).

The calibration factor is indeed constant over the thrust range. Then, the mean factor $\gamma=<\gamma_{i}>$ will be taken to convert thrust measurements. In this case, the mean calibration factor would be around $2 \mathrm{mV} / \mu \mathrm{N}$ for all the thrust levels. Balance calibration is performed before every series of thrust measurement. It should be noted that the dayto-day repeatability of the calibration coefficient is very good, which strengthens the validity of the method.

\section{E. Signal Acquisition}

During the acquisition, the signals of forward power, reflected power, Faraday probe current and PID output $\left(V_{P I D}\right)$ are recorded by a National Instrument NIPCI-6281 (16 channel 18 bits, $\left.500 \mathrm{kHz}\right)$ acquisition board. 
Anti-aliasing low-pass Butterworth type filters (SRS SIM965) with a $24 \mathrm{~dB} /$ octave slope are used for all channels. The cutoff frequency is set at $20 \mathrm{~Hz}$ for the capacitive sensor and at $1 \mathrm{~Hz}$ for the other channels. The data acquisition is done at $40 \mathrm{~Hz}$ sampling frequency.

The forward and reflected powers are used to calculate the power transmitted in the plasma. They are measured "in-line" with a Werlatone C6187 dual coupler and diode detectors (JFW 50D-052) that are calibrated using a power sensor (Ladybug 478A).

\section{F. Thrust measurement procedure and post-processing}

Fig. 9 shows a typical acquisition of the PID output signal during a thrust measurement of the ECR thruster. The first peak corresponds to the thruster ignition. The thrust amplitude is quite high because of the injection of a larger mass flow rate during a short period. The operating conditions (mass flowrate and power) are then adjusted, and the properties of the thruster are monitored during its stabilization.

Once the thruster has reached a steady-state regime (after $\sim 1$ minute) the microwave power is turned off. The thrust value is obtained by measuring the step of PID voltage at the plasma extinction. After extinction the thruster is still fed with xenon, and a cold gas thrust is applied to the thruster. The thrust values that are presented in this paper are not corrected for this residual force. Without plasma, the specific impulse in cold gas mode has been measured around $20 \mathrm{~s}$. The fraction of cold gas thrust represents between $2 \%$ and $5 \%$ of the measured thrust in the mass flowrate range tested here.

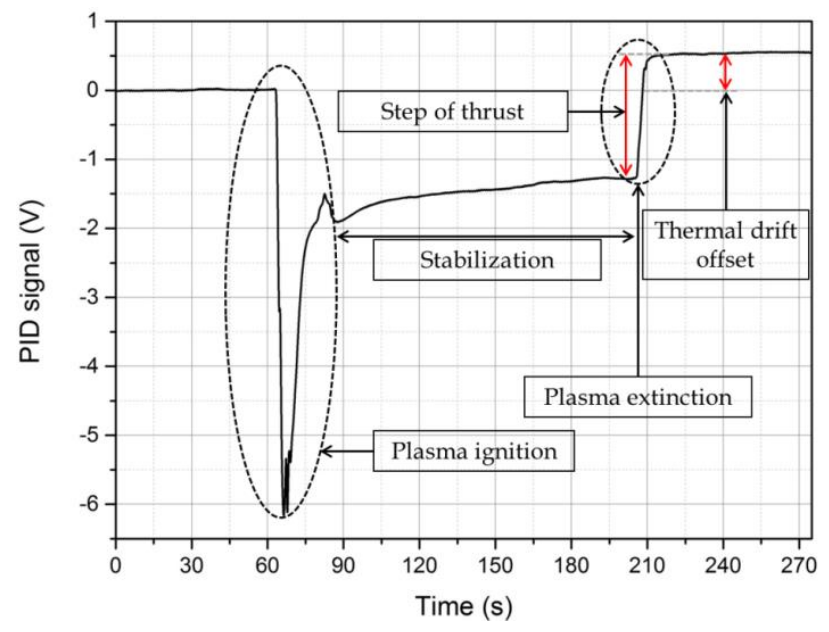

Fig. 9 Typical thrust signal during a thrust measurement acquisition.

One of the main requirements to perform a thrust measurement is that the thermal drift on the sensors must be low enough so that the step amplitude can be measured. The dielectric losses in the microwave cables and the 
charged particles flux on the walls of the plasma source induce a heating of the balance arm and a thermal dilation of the materials. The center of equilibrium of the pendulum is then moved, which produces the drift seen on the thrust signal. No significant effect of the temperature on the calibration coefficient was noticed for this balance. As can be seen in Fig. 9, the thrust step is easily detected despite the thermal drift.

The signals are post-processed in order to have a precise and systematic way to analyze the results. The procedure is as follows: first, a moving average of the data on 100 points (i.e. a bandwidth of $0.4 \mathrm{~Hz}$ for an acquisition frequency of $40 \mathrm{~Hz}$ ) is applied; forward and reflected powers are then combined together to obtain the power transmitted to the thruster; finally, the step of PID signal is converted into thrust using the calibration factor.

\section{G. Electrostatic diagnostics}

Another method to evaluate the thruster performances is to calculate the thrust from electrostatic probes measurements.

The thrust $T$ can be estimated from the angular profile of the ion current density $J_{i}$ and from the mean ion velocity $v_{i}$ at centerline (assuming that the velocity is uniform over the angular profile, which has been shown in [13]). Both measurements are performed with a gridded Faraday probe that is described in [12]. The expression of the thrust is:

$$
T=\int_{-\pi / 2}^{\pi / 2} \frac{M_{i}}{e} J_{i}(\varphi) 2 \pi D^{2} v_{i} \sin (\varphi) \cos (\varphi) d \varphi
$$

where $M_{i}$ is the ion mass, $e$ the elementary charge, $D$ the distance between the probe and the axis, and $\varphi$ is the angle of rotation of the probe (see Fig. 10).

Eq.(4) is valid only if the plasma beam is axisymmetric (the probe can move only in a plane) and for singly ionized ions (multi-ionized ions are neglected).

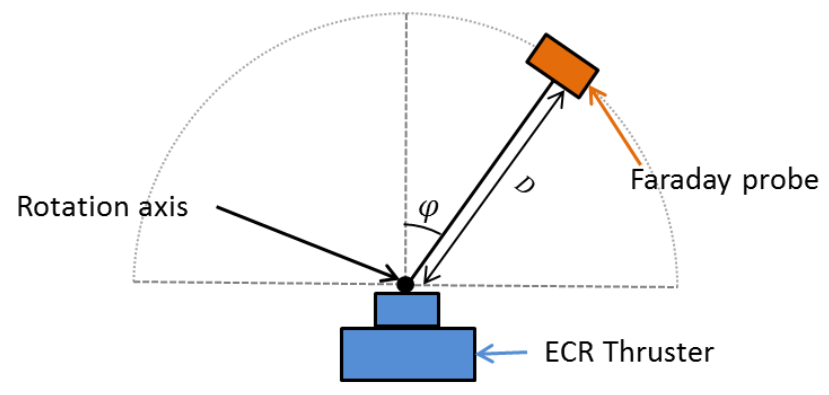

Fig. 10 Schematic of the Faraday probe diagnostic. 
A rotation stage makes the Faraday probe rotate around the ECR thruster in order to perform the angular scans (Fig. 10). The probe is placed $26.5 \mathrm{~cm}( \pm 0.5 \mathrm{~cm})$ away from the thruster for all the measurements presented here. The probe consists of a collector and a grid with a collection aperture diameter of $6 \mathrm{~mm} \pm 0.5 \mathrm{~mm}$ and a transparency of $70 \% \pm 10 \%$. For the measurement of ion current density (Fig. 11 top), the collector is biased negatively and the current is taken in the ion saturation zone of the IV curve (typically at $-300 \mathrm{~V}$ ). The grid is floating in order to avoid sheath expansion issues. No noticeable differences are observed when the grid is grounded). The collected ion current is measured with a Keithley picoammeter or with a shunt resistor. As can be seen on Fig. 12, the angular profile of ion current density has two distinctive characteristics. First, the profile is not peaked on centerline: two symmetric peaks are observed at $-5^{\circ}$ and $+5^{\circ}$. This could be due to non-homogeneities of the neutral gas injection (the gas is injected through the two holes in the backplate), which creates variations of plasma density in the source and in the plume. Second, there is a residual ion current at $90^{\circ}$. This could be due to the presence of ambient plasma produced by ionizing collisions of neutrals with electrons from the plume.

The mean ion velocity in eq. 4 can be calculated from the mean ion energy:

$$
v_{i}=\sqrt{\frac{2 E_{i}}{M_{i}}}
$$

The mean ion velocity is measured using the Langmuir characteristics of the Faraday probe [12,33]. The mean ion energy is deduced from the first derivative of the current (Fig. 11 bottom). With a single grid probe, this method is not able to determine the full ion energy distribution function with a good accuracy because of the disturbing presence of electrons from the beam and secondary electrons produced at the surface of the grid. However the mean ion energy calculated with this method is trustworthy and has been verified by comparison with a commercial ion energy analyzer. This method enables measuring the total ion energy (which is the sum of ion kinetic energy and ion potential energy) at the probe location with an error of approximatively $3 \%$. Assuming the conservation of total ion energy in the magnetic nozzle, the measured energy value is the kinetic energy that ions would have in a region where the plasma potential is close to zero (i.e. in the far plume). Depending on the real potential drop in the magnetic nozzle, the mean ion velocity can be overestimated. 

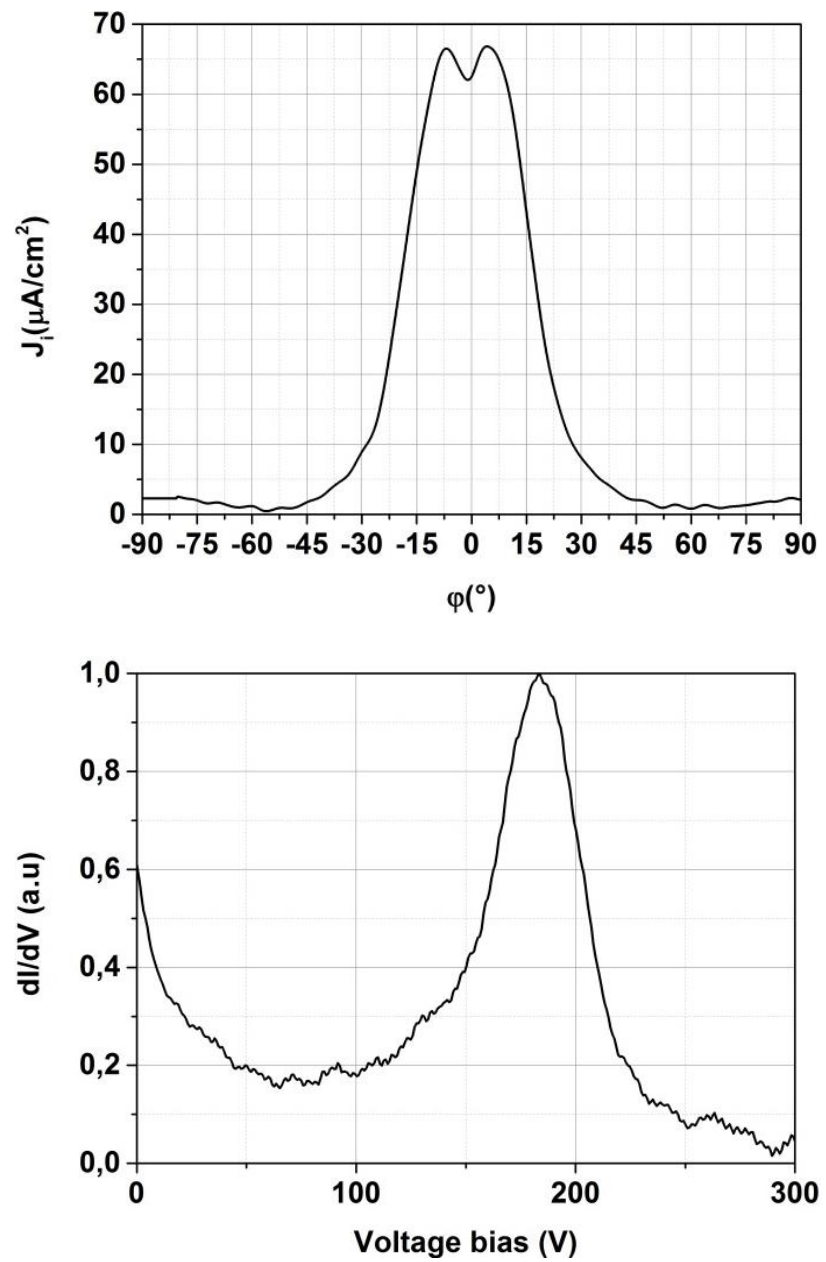

Fig. 11 On the top, typical angular profile of the ion current density. On the bottom, example of the first derivative of the ion current with respect to the bias voltage on the collector of the Faraday probe.

\section{Thrust measurement results}

The standard performance indicators for the thruster technologies are reminded here. First, the total efficiency is given by:

$$
\eta_{T}=\frac{T^{2}}{2 Q_{m} P}
$$

the specific impulse can be expressed as: 


$$
I_{S P}=\frac{T}{Q_{m} g}
$$

and the Thrust To Power Ratio is: TTPR=T/P.

$Q_{m}$ is the input massflow, and $g=9.8089 \mathrm{~m} / \mathrm{s}^{2}$ the gravitation force acceleration. In the following, the thrust $T$ and these indicators will be used to characterize the performances of the thruster. For all performance indicators that are used in his article, $P$ is the microwave power deposited in the plasma, (taking into account the losses in the microwave line between the coupler and the plasma source).

\section{A. Uncertainties of the direct thrust measurement.}

The measurement uncertainties have been calculated by error propagation of the elementary error sources.

Table 2 lists the uncertainties of the different quantities useful for the determination of the performance indicators $\left(T, I_{s p}, \eta_{T}, \mathrm{TTPR}\right)$.

Table 2 Uncertainty budget for the direct thrust measurement with the pendulum balance

\begin{tabular}{c|c|c}
\hline \hline Quantity $X_{i}$ & Meaning & Uncertainty $\Delta X_{i}$ \\
\hline \hline$V_{P I D}(V)$ & PID step signal & $20 \times 10^{-3}$ \\
\hline$V_{i}(V)$ & PID calibration signal & $30 \times 10^{-3}$ \\
\hline$L_{T}(m)$ & Balance arm length & $2 \times 10^{-3}$ \\
\hline$L_{i}(m)$ & Calibration arm length until slit $i$ & $5 \times 10^{-4}$ \\
\hline$m_{i}(\mathrm{~kg})$ & Calibration mass & $10^{-8}$ \\
\hline$g\left(\mathrm{~m} / \mathrm{s}^{2}\right)$ & Gravity acceleration constant & $<10^{-4}$ \\
\hline$Q_{m}(S C C M)$ & Mass-flow rate & $0.01+0.005 Q_{m}$ \\
\hline$P(W)$ & MW power & $0.04 P$ \\
\hline
\end{tabular}

The uncertainty on the power deposited in the plasma comes from the measurement of diode detector voltage (which depends on the power level), from the attenuation value in the microwave line, and from the directivity of the coupler that induces a non-linear behavior.

The uncertainty over the thrust $T$ is expressed as:

$$
\Delta T(m N)=\sqrt{\left(\frac{\Delta V_{P I D}}{\gamma}\right)^{2}+\left(\frac{\Delta V i}{\gamma}\right)^{2}+\left(\left(\frac{\Delta L_{T}}{L_{T}}\right)^{2}+\left(\frac{\Delta L_{i}}{L_{i}}\right)^{2}\right) T^{2}}
$$

Concerning uncertainties of the others quantities deduced from the thrust, one has the uncertainty over the specific impulse $I_{S P}$ : 


$$
\left(\frac{\Delta I_{S P}}{I_{S P}}\right)^{2}=\left(\frac{\Delta T}{T}\right)^{2}+\left(\frac{\Delta Q_{m}}{Q_{m}}\right)^{2},
$$

the uncertainty over the TTPR:

$$
\left(\frac{\Delta T T P R}{T T P R}\right)^{2}=\left(\frac{\Delta T}{T}\right)^{2}+\left(\frac{\Delta P}{P}\right)^{2}
$$

and the uncertainty over the total efficiency $\eta_{T}$ :

$$
\left(\frac{\Delta \eta_{T}}{\eta_{T}}\right)^{2}=2\left(\frac{\Delta T}{T}\right)^{2}+\left(\frac{\Delta Q_{m}}{Q_{m}}\right)^{2}+\left(\frac{\Delta P}{P}\right)^{2}
$$

The relative uncertainties are given with respect to the thrust $T$ on Fig. 12.

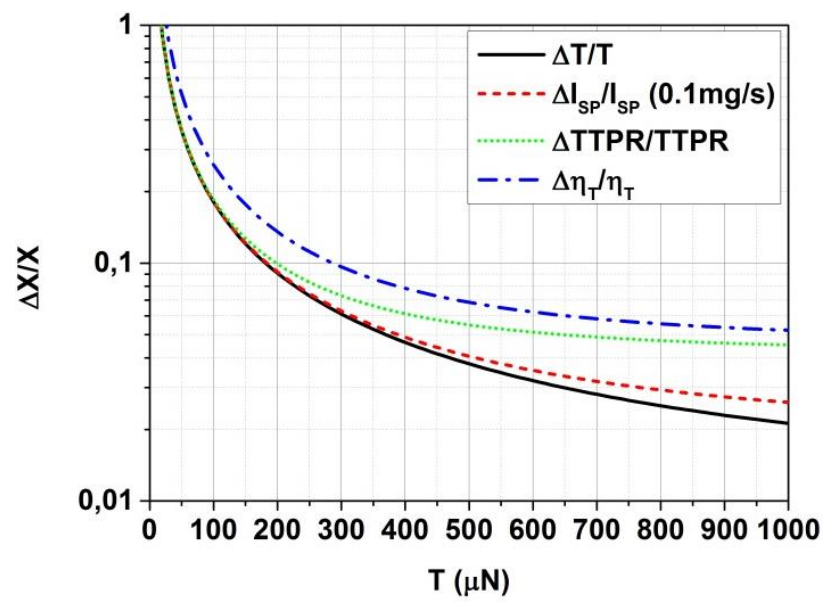

Fig. 12 Theoretical relative uncertainties of the performance parameters with respect to the thrust

In what follows, all the uncertainties will be visible as error bars on the figures.

\section{B. Parametric study with conducting walls}

The Fig. 13 shows the performances of ECR-PM-V1 thruster for different operating conditions. The thrust and the efficiency are presented with respect to the absorbed microwave power for four different xenon mass flowrates: $0.06,0.08,0.1$ and $0.15 \mathrm{mg} / \mathrm{s}$.

At $0.08 \mathrm{mg} / \mathrm{s}$, when the microwave power is increased from $26 \mathrm{~W}$ to $50 \mathrm{~W}$, the measured thrust increases from 560 to $680 \mu \mathrm{N}$, while the thruster efficiency drops from 7.7\% to 5.5\%. Generally, the thrust increases with absorbed power and mass flow rate, with a maximum thrust of $960 \mu \mathrm{N}$ measured at $0.15 \mathrm{mg} / \mathrm{s}$ and $51 \mathrm{~W}$. On the other hand, 
the total efficiency shows no clear trends: for $0.06 \mathrm{mg} / \mathrm{s}, 0.08 \mathrm{mg} / \mathrm{s}$, and $0.1 \mathrm{mg} / \mathrm{s}, \eta_{T}$ decreases with power, whereas efficiency seems to have an optimum at $0.125 \mathrm{mg} / \mathrm{s}$, and is steadily increased with power at $0.15 \mathrm{mg} / \mathrm{s}$.
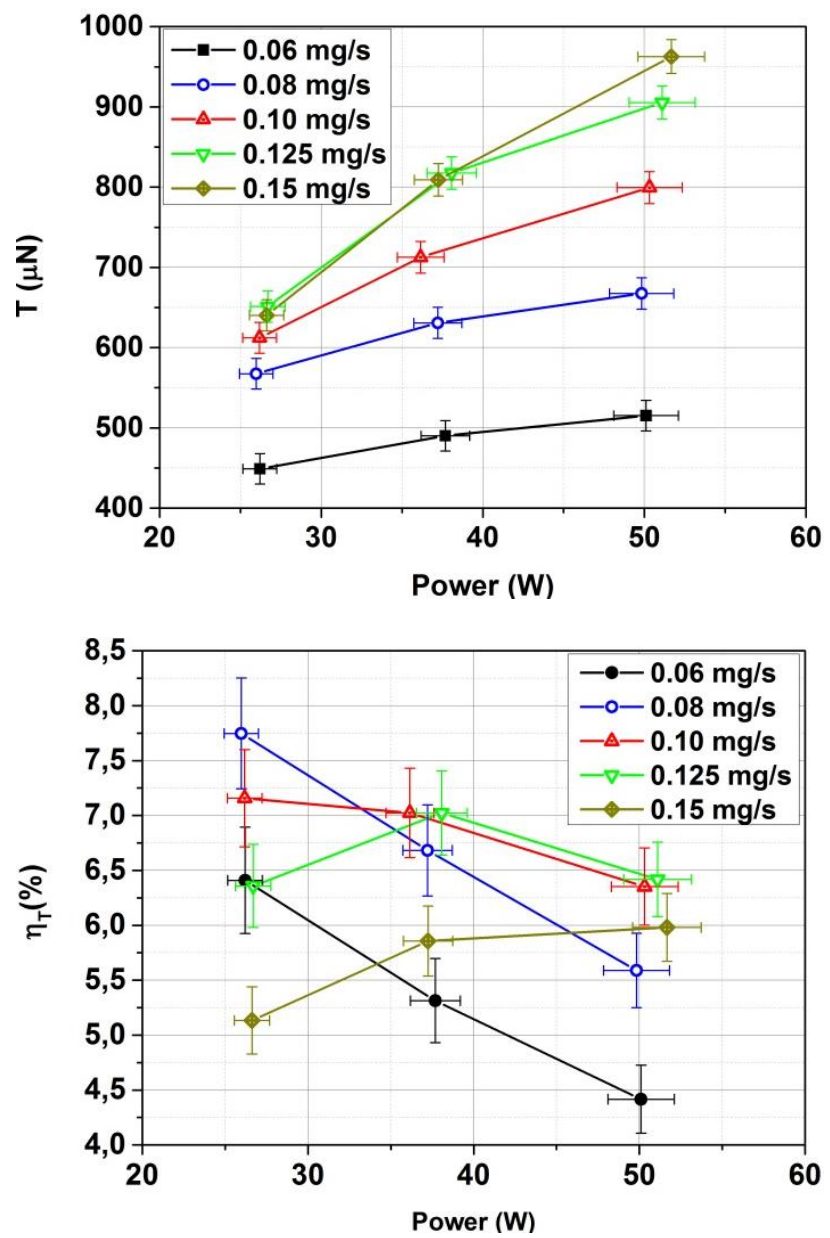

Fig. 13 Evolution of thrust (top) and total efficiency (bottom) with the power for five different mass-flow rates.

A convenient way to analyze these results is to plot the performances versus the ratio of the mass flow rate to the absorbed power $\mathrm{Q}_{\mathrm{m}} / \mathrm{P}$. Fig. 14 presents the $I_{S P}$ as a function of $\mathrm{Q}_{\mathrm{m}} / \mathrm{P}$ ratio for data obtained with the thruster configuration shown on Fig. 13. The specific impulse steadily drops from $1000 \mathrm{~s}$ for low $\mathrm{Q}_{\mathrm{m}} / \mathrm{P}$ to $400 \mathrm{~s}$ at $6 \mu \mathrm{g} / \mathrm{J}$. One can notice the linear trend of the data in this range of mass flow rate and power. This behavior enables to adjust the specific impulse of the thruster by tuning the operating condition. 


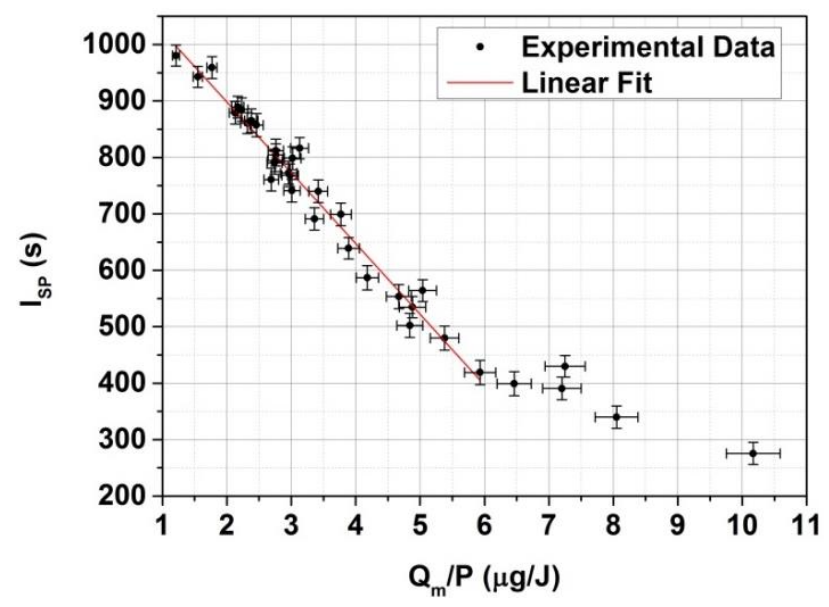

Fig. 14 Specific Impulse $\left(I_{S P}\right)$ with respect to the mass-flow rate to power ratio. The experimental data are fitted with a linear regression below $6 \mu \mathrm{g} / \mathrm{J}$.

Even if the underlying physics is not fully understood, some informations can be pulled out from this observation. The most important of them is the behavior of the other quantities ( $T$, TTPR, and $\left.\eta_{T}\right)$ with respect to the operating conditions.

In the linearity range (between 1 and $6 \mu \mathrm{g} / \mathrm{J}$ ) the $I_{S P}$ can be written as:

$$
I_{S P}=-\alpha \frac{Q_{m}}{P}+\beta
$$

with $Q_{m}$ the mass flow rate, $P$ the absorbed power, $\alpha$ and $\beta$ positive contants.

One can deduce expressions for the Thrust To Power Ratio (TTPR) and for the total efficiency $\left(\eta_{T}\right)$ :

$$
\begin{gathered}
\text { TTPR }=-\alpha g\left(\frac{Q_{m}}{P}\right)^{2}+\beta g\left(\frac{Q_{m}}{P}\right) \\
\eta_{T}=\frac{g^{2}}{2}\left(\alpha^{2}\left(\frac{Q_{m}}{P}\right)^{3}-2 \alpha \beta\left(\frac{Q_{m}}{P}\right)^{2}+\beta^{2}\left(\frac{Q_{m}}{P}\right)\right)
\end{gathered}
$$

It means that the performance indicators only depends on one parameter, $\mathrm{Q}_{\mathrm{m}} / \mathrm{P}$, for a given thruster configuration in this range of power and mass flow rate $(20-50 \mathrm{~W}, 0.06-0.15 \mathrm{mg} / \mathrm{s})$. The thruster efficiency reach its maximum value when the first derivative of eq. (9) vanishes, giving: 

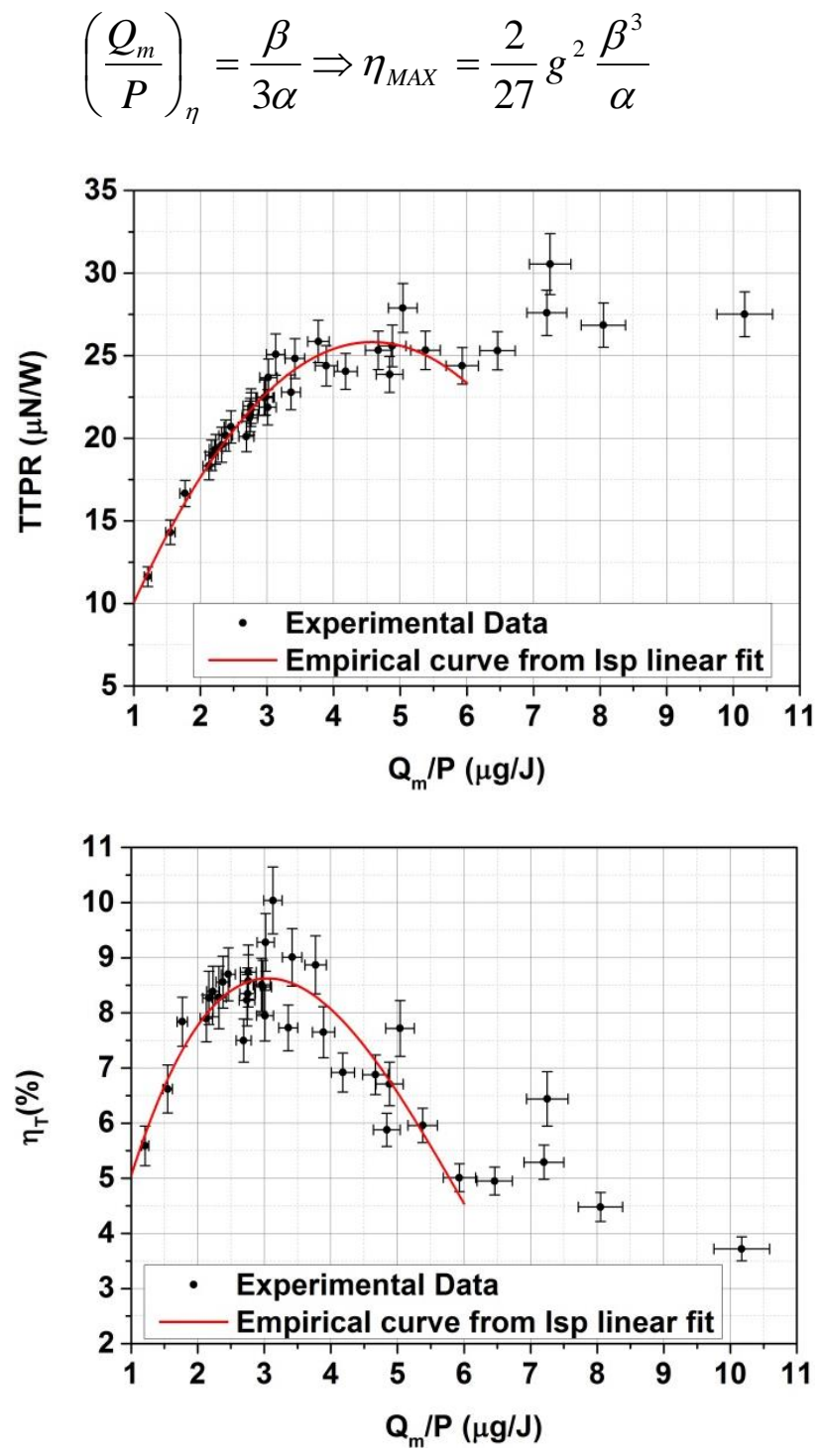

Fig. 15 Thrust to power ratio (top) and total efficiency (bottom) with their empirical curve deduced from $I_{S P}$ linear fit.

In the current configuration, the values for $\alpha$ and $\beta$ obtained with a linear fit on the Fig. 14 are 103.04 and 1001.4, respectively. Experimental data of the TTPR (top) and thruster efficiency (bottom) versus $Q_{m} / P$ are shown on Fig. 15. The red curve stands for the efficiency calculated from the $I_{\text {sp }}$ fit (Fig. 14) and is computed in the linear range of the data (up to $6 \mu \mathrm{g} / \mathrm{J}$ ). In this range, TTPR increases up to $\mathrm{Q}_{\mathrm{m}} / \mathrm{P}=\beta / 2 \alpha \sim 4 \mu \mathrm{g} / \mathrm{J}$ where a value around $25 \mu \mathrm{N} / W$ is reached. Concerning the total efficiency (Fig. 15 bottom), a maximum value is clearly visible around $8.5 \%$ for $\mathrm{Q}_{\mathrm{m}} / \mathrm{P} \sim 3 \mu \mathrm{g} / \mathrm{J}$. It should be noticed that slightly higher TTPR can be obtained for higher $\mathrm{Q}_{\mathrm{m}} / \mathrm{P}$ 
(i.e. above the linearity range of the $\mathrm{I}_{\mathrm{sp}}$ ). However the thruster efficiency decreases in these conditions (less than $5 \%)$.

The fact that the performances depend on only one parameter $\left(Q_{m} / P\right)$ for a given thruster configuration presents several advantages. First, it enables to change the thrust while keeping a maximum efficiency: the mass flow rate and the power can be increased in order to keep $Q_{m} / P$ constant. Moreover, the mass-flow to power ratio $Q_{m} / P$ can be varied in order to select the thruster operation mode: if the available power is the main limit, one can adjust the ratio to optimize the TTPR; if the total mass of propulsive gas is the main limit, a larger $I_{s p}$ can be obtained by reducing the ratio. And as a compromise for both the gas and power consumptions, the total efficiency can be adjusted according to eq. (10).

\section{Insulating walls}

In the following experiments, the inner surface of the source cylinder was covered with an insulating material (a thin layer of Kapton polyimide) to study the effect of the wall properties on the thruster performances. Fig. 16 compares the thrust and efficiency with and without dielectric layer for a mass flow rate of $0.1 \mathrm{mg} / \mathrm{s}$ of xenon. The measured thrust is raised by about $20 \%$ with non-conducting walls in the source. In the meantime, the thruster efficiency is increased from $7 \%$ to $10.5 \%$ at $40 \mathrm{~W}$, i.e. an improvement of $40 \%$ of the performances. 

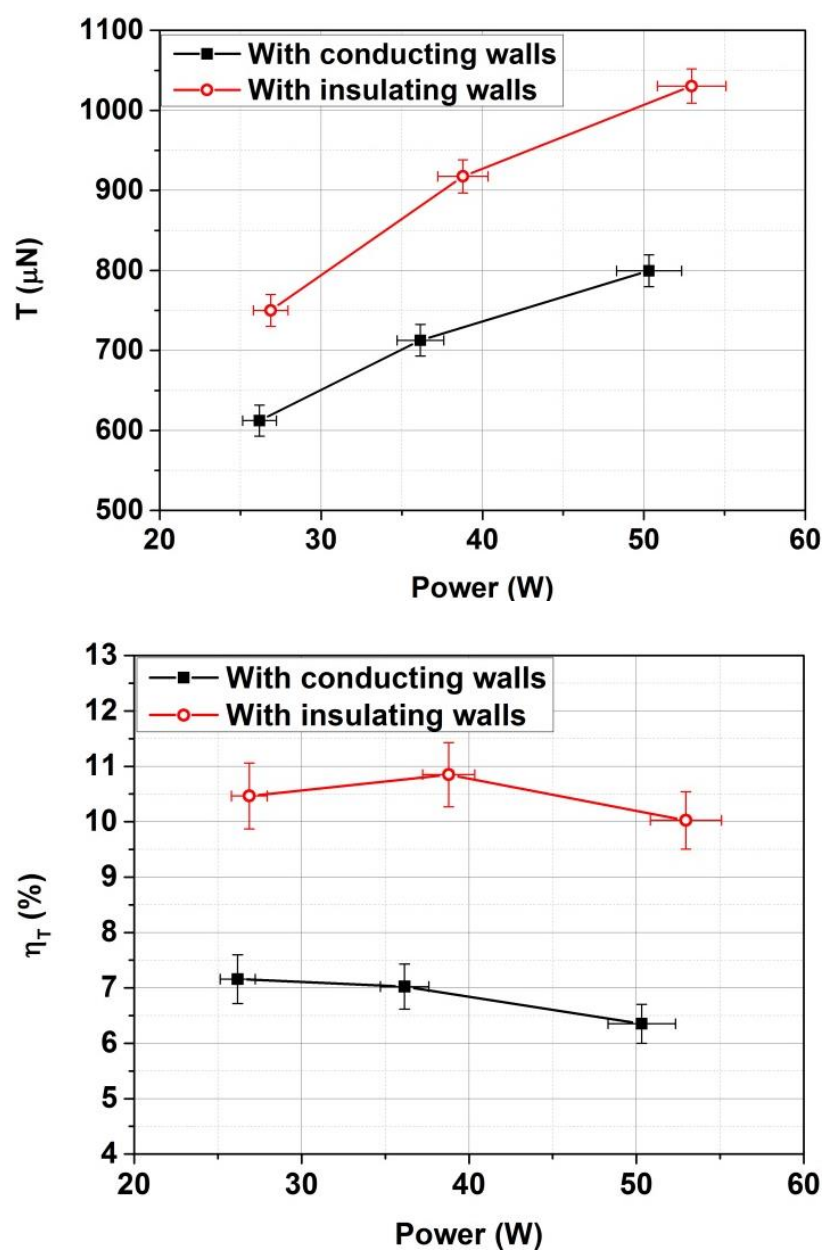

Fig. 16 Comparison of measured thrust (top) and total efficiency (bottom) between metallic walls and dielectric walls configurations at $0.1 \mathrm{mg} / \mathrm{s}$.

The experimental data with metallic and dielectric walls are expressed as a function of $Q_{m} / P$ ratio in Fig. 17 . One can notice the linear behavior for both cases but with different values for $\alpha$ and $\beta$. However, the ratio $\beta / \alpha$ is very similar $(9.7 \mu \mathrm{g} / \mathrm{J}$ vs $10.2 \mu \mathrm{g} / \mathrm{J})$, which means that the optimum operating condition given by eq. (10) is almost the same in both cases. 


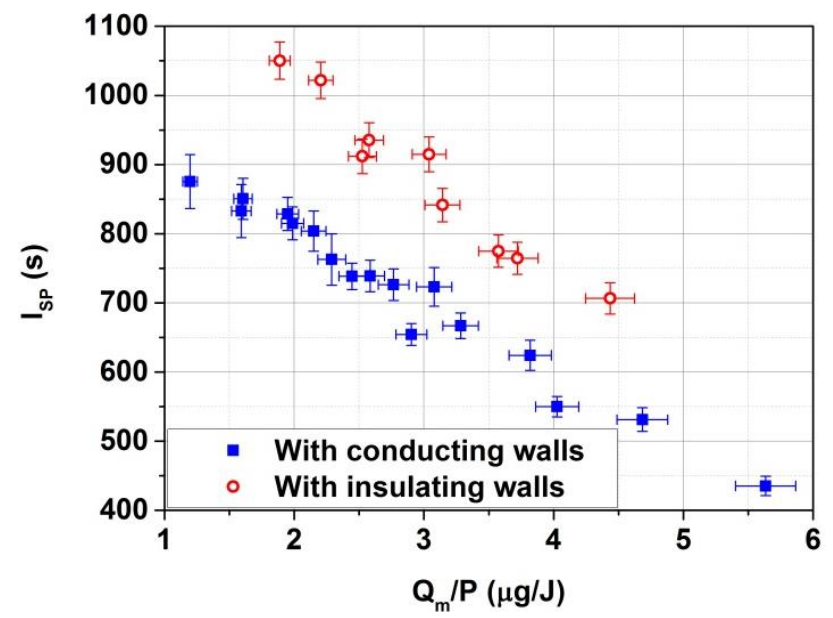

\section{Fig. 17 Comparison of the Specific Impulse $\left(I_{S P}\right)$ versus mass-flow rate to power ratio for metallic and dielectric walls.}

Further experiments have shown that the total ion beam current is increased in the presence of insulating walls while the mean ion energy remains constant (not shown here).

This behavior means that either the ionization rate is higher or the plasma confinement is increased in the plasma source with insulated walls. Two phenomena could explain this effect: Secondary electron emission (SEE) and Simon short circuits. First, the additional dielectric polyimide layer has a different SEE yield than the original aluminum structure. The electron balance in the plasma is then changed, leading to a variation of the ionization rate, of the potential drop in the plasma sheath near the walls, and finally of the charged particle flux on the walls of the source [34]. Second, it is known that the conducting properties of the walls can modify the ion diffusion, allowing cross-field diffusion [35]. This could affect the plasma confinement and consequently the ion production efficiency. Finally the combination of these two phenomena could modify the axial distribution of ion bombardment on the walls and therefore the global emission flux of secondary electrons.

\section{Comparisons with electrostatic diagnostics}

A comparison is made here between the two methods used to measure the performances of the ECR-PM-V1 thruster with conducting walls: direct measurement with the balance and indirect measurement with the electrostatic probe (i.e. Faraday probe). The global performance indicators $\left(T\right.$ and $\left.\eta_{T}\right)$, and the detailed efficiencies (mass efficiency $\eta_{m}$, energy efficiency $\eta_{e}$ and divergence efficiency $\eta_{D}$ ) are shown and discussed. The detailed efficiencies are deduced from Faraday probe measurements. One can remind the formula of the total efficiency: 
$\eta_{T}=\eta_{D}^{2} \eta_{e} \eta_{m}$, with $\eta_{D}=\frac{T}{Q_{m} v_{i}}, \eta_{e}=\frac{I_{t o t} E_{i}}{P}$ and $\eta_{m}=\frac{I_{t o t} M_{i}}{e Q_{m}} . P$ is the microwave power deposited into the thruster (taken into account the losses in the cables and the impedance matching of the plasma).

Fig. 18 shows a comparison of the thrust (top) and of the total efficiency (bottom) obtained with direct thrust measurements and with electrostatic probe measurements. Experiments are performed at $0.1 \mathrm{mg} / \mathrm{s}$ for different values of power.
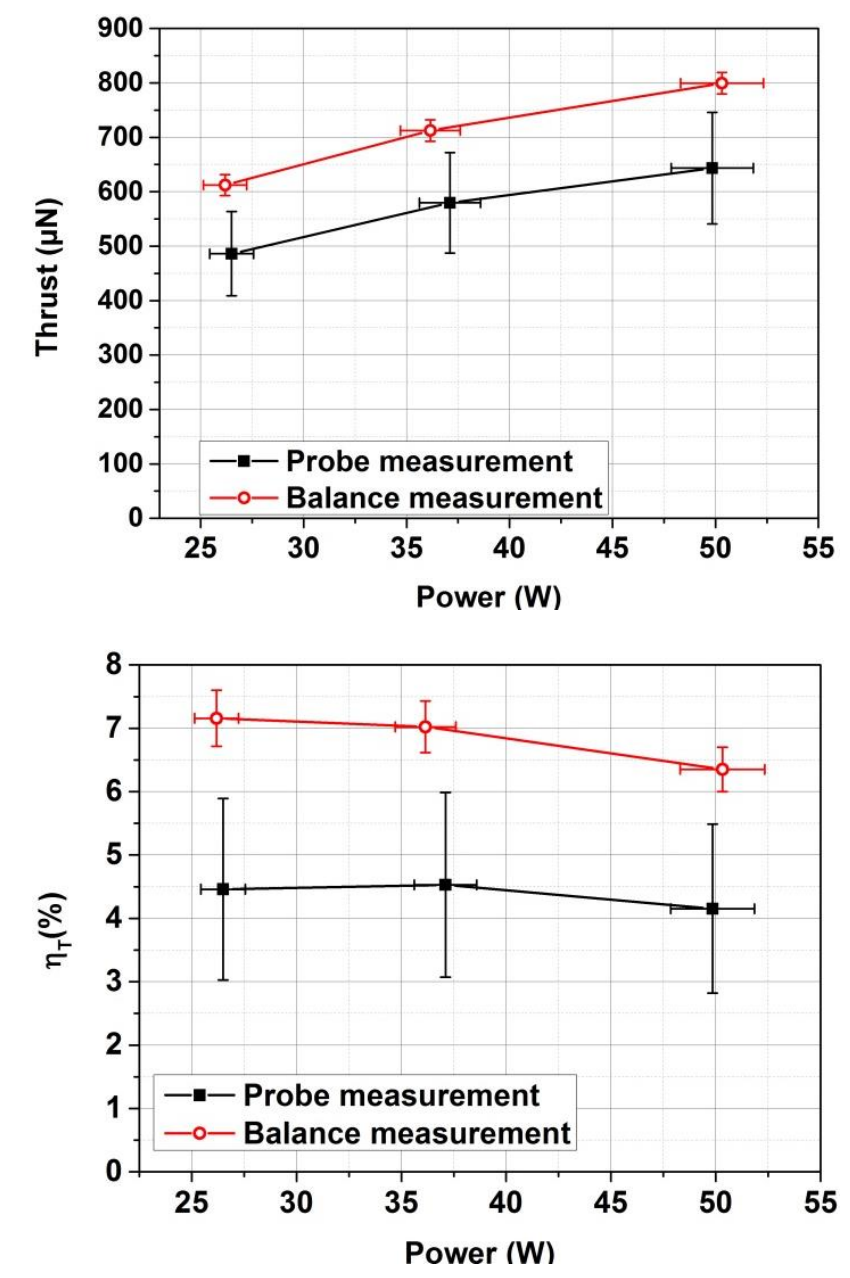

Fig. 18 Comparison of thrust measurements (top) and thruster efficiencies (bottom) between direct (balance) and indirect (Faraday probe) measurements.

The error bars included in Fig. 18, which correspond to the uncertainties of the probe measurement, have been determined according to the recommended practice for the use of Faraday probes [36]. They have been calculated 
using eq. (4), taking in account the uncertainty on the distance $D$ of the probe from the thruster; on the collector diameter; on the grid transparency; on the alignment with thrust axis; and on the ion energy. The current leakage in the measurement circuit and the error on the probe angle are negligible. The effect of secondary electron emission and the possible sheath expansion beyond the grid have not been taken into account.

For all microwave power levels, the thrust that is directly measured with the balance is about $20 \%$ higher than the estimation from the probes measurements. This leads to greater values of efficiency obtained with the balance. The maximum measured thrust is around $800 \mu \mathrm{N}$ with the balance and $650 \mu \mathrm{N}$ with the probe at approximatively 50 W. Nevertheless, both methods show the same trends. In particular, the linear behavior of the $I_{S P}$ with respect to the mass-flow to power ratio $Q_{m} / P$ has also been confirmed with the probe measurements.

Although the thrust value inferred from probe measurements is less reliable than the thrust value directly measured with the balance, the probe results give more insight into the performance of the thruster.

Fig. 19 shows the efficiencies of the thruster (mass utilization, energy, divergence and total) with respect to the $\mathrm{Q}_{\mathrm{m}} / \mathrm{P}$ ratio. Different trends are observed. The total efficiency $\eta_{T}$ is maximum for similar operating conditions $(\sim 3 \mu \mathrm{g} / J)$ with the direct and indirect method. The divergence efficiency $\eta_{D}$ is almost constant in the whole range (around 80\%), which means that power and mass-flow rate have no influence on the angular distribution of ion current in the plume. The energetic efficiency $\eta_{e}$ increases between 1 and $3 \mu \mathrm{g} / \mathrm{J}$ and remains constant around 20\% above this value. On the opposite, the mass efficiency $\eta_{m}$ is maximum from 1 to $3 \mu \mathrm{g} / \mathrm{J}$ (around $40 \%$ ) and tends to decrease for higher $Q_{m} / P$.

The variations of the detailed efficiencies can enlighten some physical mechanisms in the source. 


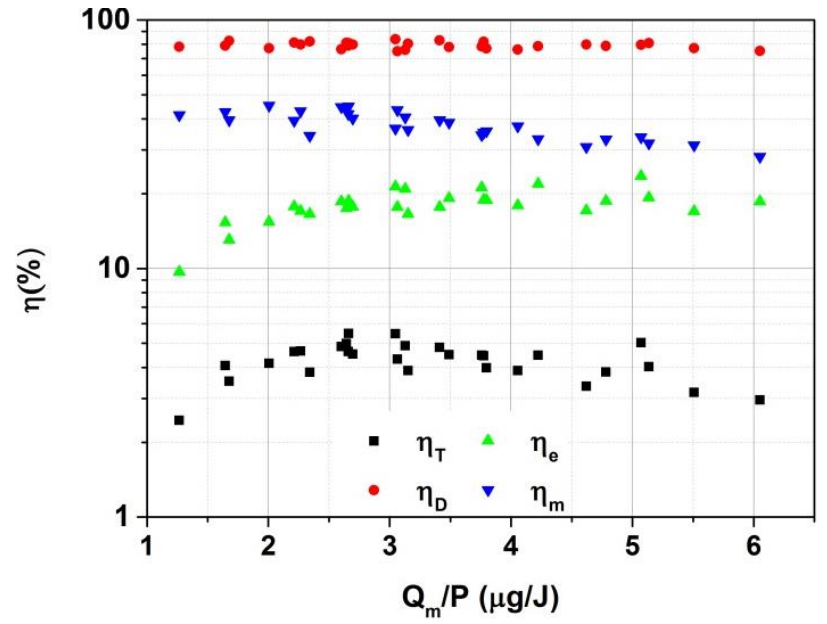

Fig. 19 The four different types of efficiencies against the mass-flow to power ratio for the same data set.

High $Q_{\mathrm{m}} / \mathrm{P}$ correspond to low reduced electric field $(E / N)$. The electron temperature is then lower, and the ionization is less efficient leading to a lower mass efficiency. On the other hand, low mass-flow to power ratio leads to higher electron temperature and a better ionization of the propellant gas, which could explain the trend of $\eta_{m}$ However, electron losses on the walls also increase with the temperature. With a floating source, this finally leads to higher ion losses on the walls and a decrease of the energy efficiency. The formation of multiply charged ions could also play a role in the energy efficiency.

It is noteworthy that the total efficiency of the ECR thruster is here limited by the energy efficiency $\eta_{e}$. The main power losses in electrodeless plasma thrusters are the propellant ionization and the plasma losses on the radial and back walls of the source. The plasma losses depend on the electron temperature and on the magnetic confinement of the source. An analytical model of a helicon discharge has shown that the performances could be significantly improved by increasing the magnetic field [14]. This is a possible way of improving the ECR thruster.

The differences between the direct (balance) and the indirect (probe) measurements could have multiple sources and are probably not only due to the uncertainty. First, it could be a wrong assumption in the method used to compute the thrust such as the axisymmetry of the beam for example. Also, it was observed that the Faraday probe significantly perturbs the thruster. The direct thrust measurements on the balance are indeed affected by the presence of the probe. When the Faraday probe is in front of the thruster $\left(\varphi=0^{\circ}\right)$, the measured thrust is typically $10 \%$ lower than when the probe is at $\varphi=90^{\circ}$, so the efficiency is about $20 \%$ lower. However, this effect by itself is not sufficient to explain the relative gap between the direct and indirect thrust measurements. The effect of the probe on 
the thruster is not understood yet, but the diagnostic is clearly intrusive for the ECR thruster. Note that in all the direct measurements presented in the paper were performed with the probe at $\varphi=90^{\circ}$.

Finally, charge exchange collisions with the background neutrals and with the plume neutrals could be an issue for the characterization of electric thrusters because it could affect the ion current distribution and the mean ion energy. However, in the conditions of our experiments (background pressure of $5 \times 10^{-6}$ to $10^{-5}$ mbar), the mean free path for charge exchange collision with neutrals from the background has been estimated to be in the range $5 \mathrm{~m}$ to $20 \mathrm{~m}$ with ions between 50 and $300 \mathrm{eV}$, using the cross sections that can be found in the literature [37]. This value is one to two orders of magnitude higher than the distance between the probe and the thruster, so charge exchanges with background neutrals can be neglected. There is still the possibility of charge exchange collisions with nonionized xenon that exit the thruster. However, normalized angular profiles of ion current density have been compared for different mass-flow rates and no differences have been observed. Therefore the charge exchange collisions with plume neutrals have no significant effect on probe measurements.

\section{Conclusion}

In this paper, the first direct thrust measurements on an ECR plasma thruster have been performed. A pendulum thrust balance is used in the null mode with a PID controller. The maximum measured thrust is about $1 \mathrm{mN}$ with a microwave power of $53 \mathrm{~W}$ and a xenon mass flowrate of $0.1 \mathrm{mg} / \mathrm{s}$. The best thruster efficiency with the current version of permanent magnet thruster is about $11 \%$ at $39 \mathrm{~W}$ and $0.1 \mathrm{mg} / \mathrm{s}$ (with dielectric walls). The specific impulse can be as high as 1050s.

It was observed that the $I_{S P}$ follows a linear law with respect to the mass-flow rate to power ratio $\left(\mathrm{Q}_{\mathrm{m}} / \mathrm{P}\right)$ for a given thruster geometry and magnetic topology. Consequently, the total efficiency $\left(\eta_{T}\right)$ only depends on $\mathrm{Q}_{\mathrm{m}} / \mathrm{P}$ and can be maximized. Moreover, the operating conditions can be adjusted to favor the thrust level, the specific impulse, or the total efficiency. A further study would be required to better understand this behavior.

An important result is the significant improvement obtained when adding a dielectric layer on the metallic source walls. This leads to an increase of $25 \%$ of the thrust value. The phenomenon is either due to a change of the secondary electron emission rate or to different ion diffusion in the plasma due to electrical properties of the vessel walls. 
Finally, the comparisons between direct and indirect measurements suggest that electrostatic probes systematically underestimate the thrust by about $20 \%$, and hence the total efficiency by about $40 \%$. This could come, at least partially, from the intrusive aspect of the Faraday probe that disturbs the thruster functioning.

All the results presented in this paper are obtained with the ECR-PM-V1 permanent magnet model of the ECR plasma thruster, which appears to be less efficient than the coil version presented in previous papers (4.5\% versus $16 \%$ of total efficiency [15] when both are measured with probes). One of the reasons could be the topology of the magnetic field: the magnetic nozzle is more divergent in coil version than in the permanent magnet one. Therefore an improvement of the efficiency by a factor of 4 could be expected with an optimization of the magnetic field topology. In the future, different source geometries will be tested, and the effect of the divergence of the magnetic nozzle will be investigated, in order to optimize the design and to further improve the performances.

\section{Funding Sources}

This work was partially made in the framework of project MINOTOR that has received funding from the European Union's Horizon 2020 research and innovation program under grant agreement No 730028.

\section{References}

[1] Charles, C., "Plasmas for Spacecraft Propulsion”, Journal of Physics D: Applied Physics, Vol. 42, No. 16, 2009 , pp. 163001. doi:10.1088/0022-3727/42/16/163001

[2] Chen, F.F., "Physics of Helicon Discharges", Physics of Plasmas, Vol. 3, No. 5, 1996, pp. 1783-1793.

[3] Geller, R., "Electron Cyclotron Resonance Ion Sources and ECR Plasmas", Institute of Physics Publishing Bristol and Philadelphia, ISBN 0750301074, 1996.

[4] Arefiev, A. V. and Breizman, B. N., "Ambipolar Acceleration of Ions in a Magnetic Nozzle", Physics of Plasmas, Vol. 15, No. 4, 2008, pp. 042109. doi: $10.1063 / 1.2907786$

[5] Kosmahl, H.G., Miller, D.B. and Bethke, G.W., "Plasma Acceleration with Microwaves near Cyclotron Resonance", Journal of Applied Physics, Vol. 38, No. 12, 1967, pp. 4576-4582

[6] Sercel, J.C., "Electron-Cyclotron-Resonance (ECR) Plasma Acceleration”, AIAA Paper 87-1407, June 1987.

[7] Stallard, B.W. and Hooper, E.B., "Plasma Confinement in the Whistler Wave Plasma Thruster", Journal of Propulsion and Power, Vol. 17, No. 2, 2001, pp. 433-435. 
[8] Stallard, B.W. and Hooper, E.B, "Whistler-Driven, Electron-Cyclotron-Resonance-Heated Thruster: Experimental Status”, Journal of Propulsion and Power, Vol. 12, No. 4, 1996, pp. 814-816.

[9] Vialis, T., Jarrige, J., Packan, D., “Geometry Optimization and Effect of Gas Propellant in an Electron Cyclotron Resonance Plasma Thruster”, International Electric Propulsion Conference, Paper IEPC-2017-378, October 2017.

[10] Mazouffre, S., Largeau, G., Garrigues, L., Boniface, C., Dannenmayer, K., "Evaluation of Various Probe Designs for Measuring the Ion Current Density in a Hall Thruster Plume”, International Electric Propulsion Conference, Paper IEPC2017-336, October 2017.

[11] ONERA, INPI Brevet d'Invention, n.11 62545, 2014

[12] Lafleur, T., Cannat, F., Jarrige, J., Elias, P-Q. and Packan, D., "Electron Dynamics and Ion Acceleration in ExpandingPlasma Thrusters", Plasma Sources Science Technologies, Vol. 24, No. 6, 2015, pp. 065013 doi:10.1088/0963-0252/24/6/065013

[13] Jarrige, J., Elias, P-Q., Cannat, F. and Packan, D., “Characterization of a Coaxial ECR Plasma Thruster”, AIAA Paper 20132628, June 2013.

[14] Lafleur, T., "Helicon plasma thruster discharge model”, Physics of Plasmas, Vol.21, No. 4, 2014, pp. 043507. doi: http://dx.doi.org/10.1063/1.4871727

[15] Cannat, F., Lafleur, T., Jarrige, J., Chabert, P., Elias, P-Q. and Packan, D., “Optimization of a Coaxial Electron Cyclotron Resonance Plasma Thruster with an Analytical Model”, Physics of Plasmas, Vol.22, No.5, 2015, pp. 053503. doi: dx.doi.org/10.1063/1.4920966

[16] Little, J.M., Choueiri, E.Y., "Electron Cooling in a Magnetically Expanding Plasma”, Physical Review Letters, Vol. 117, No.22, 2016, pp.225003 doi:10.1103/PhyRevLett.117.225003

[17] Zhan, Y., Charles, C., Boswell, R., “Thermodynamic Study on Plasma Expansion along a Divergent Magnetic Field”, Physical Review Letters, Vol. 116, No. 2, 2016, pp.025001 doi: 10.1103/PhyRevLett.116.025001

[18] Correyero, S., Jarrige, J. and Packan, D., "Measurement of Anisotropic Plasma Properties along the Magnetic Nozzle Expansion of an Electron Cyclotron Resonance Thruster”, International Electric Propulsion Conference, Paper IEPC-2017437, October 2017.

[19] Jarrige, J., Elias, P-Q and Packan, D., "Measurement of Ion Acceleration in the Magnetic Nozzle of an ECR Plasma Thruster”, Space Propulsion Conference, Paper 2980728, Cologne, Germany, May 2014

[20] Cannat, F., Jarrige, J., Lafleur, T., Elias, P-Q. and Packan, D., "Experimental Geometry Investigation of a Coaxial ECR Plasma Thruster”, International Electric Propulsion Conference, Paper IEPC-2015-242/ISTS-2015-b-242, July 2015. 
[21] Polk, J.E., Pancotti, A., Haag, T., King, S., Walker, M., Blakely, J., Ziemer, J., "Recommended Practice for Thrust Measurement in Electric Propulsion Testing”, Journal of Propulsion and Power, Vol.33, No. 3, 2017, pp. 539-555 doi:10.2514/1.B35564

[22] Pavarin, D., Ferri, F., Manente, M., Lucca Fabris, A., Trezzolani, F., Faenza, M., Tasinato, L., Tudisco, O., Deangelis, R., Loyan, A., Protsan, Y., Tsaglov, A., Selmo, A., Katsonis, K., Berenguer, Ch., Packan, D., Jarrige, J., Blanchard, C., Elias, PQ., Bonnet, J., “Thruster Development Set-up for the Helicon Plasma Hydrazine Combined Micro Research Project (HPH.com)", International Electric Propulsion Conference, Germany, Paper IEPC-2011-241, September 2011.

[23] Jarrige, J., Thobois, P., Blanchard, C., Elias, P-Q., Packan, D., Fellerini, L. and Noci, G., "Thrust Measurements of the Gaia Mission Flight-Model Cold Gas Thruster”, Journal of Propulsion and Power, Vol. 30, No. 4, 2014, pp. $934-943$. doi: $10.2514 / 1 . B 35091$

[24] Takahashi, K., Lafleur, T., Charles, C., Alexander, P., Boswell, R.W., Perren, M., Laine, R., Pottinger, S., Lappas, V., Harle, T. and Lamprou, D., "Direct Thrust Measurement of a Permanent Magnet Helicon Double Layer Thruster", Applied Physics Letters, Vol. 98, No. 14, 2011, pp. 141503.

doi:10.1063/1.3577608

[25]Lafleur, T., Takahashi, K., Charles, C., and Boswell, R.W., "Direct Thrust Measurement and Modeling of Radio-Frequency Expanding Plasma Thruster”, Physics of Plasmas, Vol. 18, No. 8, 2011, pp. 080701. doi: $10.1063 / 1.3610570$

[26] Nakamura, T., Takahashi, K., Nishida, H., Shinohara, S., Matsuoka, T., Funaki, I., Tanikawa, T. and Hada, T., "Direct Measurement of Electromagnetic Thrust of Electrodeless Helicon Plasma Thruster Using Magnetic Nozzle”, World Academy of Science, Engineering \& Technologies, Vol. 6, No. 11, 2012, pp. 581-585.

[27] Correyero, S., Vialis, T., Jarrige, J. and Packan, D., "Plume Properties Measurement of an Electron Cyclotron Resonance Accelerator", Gaseous Electronics Conference, Paper GECJW4001C, October 2016.

[28] Takahashi, K., Charles, C., Boswell, R., Ando, A., "Effect of Magnetic and Physical Nozzles on Plasma Thruster Performance", Plasma Sources Science Technologies, Vol. 23, No. 4, 2014, pp. 044004. doi:10.1088/0963-0252/23/4/044004

[29] Ahedo, E. and Merino, M., “On Plasma Detachment in Propulsive Magnetic Nozzles”, Physics of Plasmas, Vol. 18, No. 5, 2011, pp. 053504. doi: $10.1063 / 1.3589268$

[30] Ahedo, E., Merino, M., “Two-Dimensional Supersonic Plasma Acceleration in a Magnetic Nozzle”, Physics of Plasmas, Vol. 18, No. 7, 2010, pp. 073501. doi: $10.1063 / 1.3442736$ 
[31] Longmier, B.W., Bering III, E.A., Carter, M.D., Cassady, L.D., Chancery, W.J, Chang Diaz, F.R., Glover, T.W., Hershkowitz, N., Ilin, A.V., McCaskill, G.E., Olsen, C.S. and Squire, J.P., “Ambipolar Ion Acceleration in an Expanding Magnetic Nozzle", Plasma Sources Science Technologies, Vol. 20, No. 1, 2011, pp. 015007. doi:10.1088/0963-0252/20/1/015007

[32] Kakami, A., Muto, T., Yano, Y. and Tachibana, T., "A Method for Evaluating the Thrust of a Space Propulsion Device with Wide Range Time Variations Using a Disturbance Observer”, Review of Scientific Instruments, Vol. 86, Vol. 11, 2015, pp. 115114.

doi: 10.1063/1.4935884

[33] Lafleur, T., "Electrostatic Probe Diagnostics for Electric Propulsion Systems”, Von Karman Institute Conference, Paper AVT 263-VKI, June 2016.

[34] Hobbs, G.D., Wesson, J.A., "Heat Flow through a Langmuir Sheath in the Presence of Electron Emission", Plasma Physics, Vol. 9, 1967, pp. 85-87

[35] Drentje A.G, "Simon Short Circuit Effect in ECRIS”, Review of Scientific Instruments, Vol. 73, No. 2, 2002, pp. 516-520. doi: $10.1063 / 1.1429315$

[36] Brown, D. L., Walker, M.L.R, Szabo, J., Huang, W., Foster, J.E., "Recommended Practice for Use of Faraday Probes in Electric Propulsion Testing”, Journal of Propulsion and Power, Vol.33, No. 3, 2017, pp. 582-612 doi: 10.2514/1.B35696

[37] Miller, J.S., Pullins, S.H., Levandier D.J., Chiu, Y., Dressler, R.A., "Xenon charge exchange cross sections for electrostatic thruster models", Journal of Applied Physics, Vol.91, No.3, 2002, pp.984-991

doi: $10.1063 / 1.1426246$ 